\title{
Risk reduction measures: adaptation and integration of the concept into risk analysis of flood protection systems
}

\author{
B. Beullac ${ }^{1, a}$, R. Tourment ${ }^{1}$, F. Gumez ${ }^{1}$ \\ ${ }^{1}$ Irstea, Aix en Provence, France
}

\begin{abstract}
Risk analysis methods are now widely used to inform and help flood protection system managers in their decision making. Identification and characterisation of risk reduction measures are among the main purposes of the risk analysis process. The risk reduction measure concept, which has first been defined for industrial applications, is now classically used in dams risk analysis. However, due to the specificities of levee systems, the definition of risk reduction measures still needs to be adapted to suit well to risk analysis of flood protection systems. The paper presents an adaptation of the risk reduction measure definition to flood protection system specificities. It details the different types of risk reduction measures that can be applied to levee systems and explains how they can be characterized to evaluate their performance. Finally, the paper presents a process to identify risk reduction measures and integrate them in the specific failure mode and effects analysis method developed by Irstea these past few years to analyse the failures of levee systems and identify the different hydraulic and structural failure scenarios of flood protection systems.
\end{abstract}

\section{Introduction}

Risk analysis methods are widely used to inform flood protection system managers and help them in their decision making. Risk analysis of levee systems, which estimates the overall level of risk associated to levee systems, requires the identification and examination of all the components that determine the risk of flooding in leveed areas. Risk reduction measures (RRM) of levee systems, which aim to limit the probability of failure of levee systems and/or the consequences of the resulting inundations in leveed areas, are one of these components.

Identification and examination of risk reduction measures are mainly conducted during the "effectiveness of existing controls" step of the levee risk analysis process (figure 1). That step of levee risk analysis deals with three different types of controls [1]:

- controls acting on extreme hydraulic events probabilities (control of water level in rivers...);

- controls acting on levee systems failure probabilities (levees inspection and maintenance, emergency actions...);

- and controls acting on the levee systems consequences estimation (emergency plans for assets security...).

In this paper, we focus on levee systems failure analysis and thus on levee systems controls.

The risk reduction measure concept, which has first been defined for industrial risk analysis [2], is now classically used for dams risk analysis [3-4]. However, due to the specificities of levee systems in terms of structures, management and interdependency with their environment, the definition of risk reduction measures still needs to be adapted to fit well to risk analysis of flood protection systems.

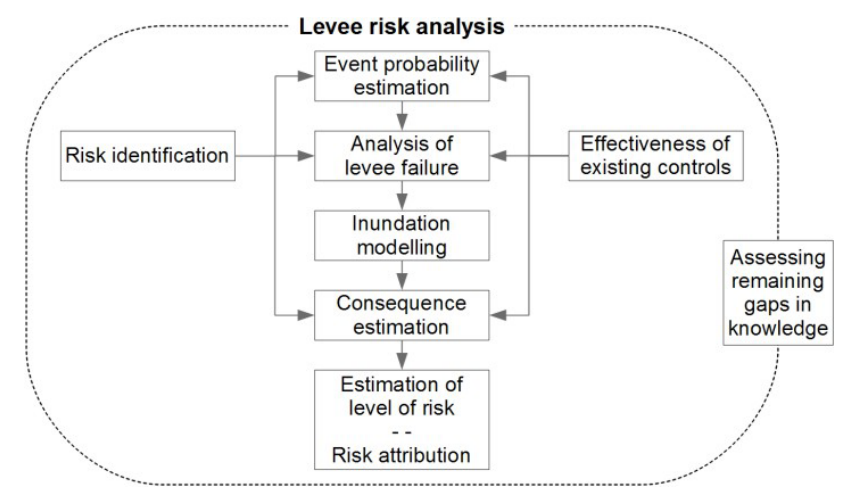

Figure 1. The different steps of the levee risk analysis process (Based on [1])

The first part of the paper presents an adaptation of the risk reduction measure definition to flood protection system specificities. It details the different types of risk reduction measures that could be applied to levee systems and explains how they can be characterized to evaluate their performance. The paper also explains the difference between measures which continuously ensure levee system efficiency and security (inspection and maintenance, emergency management and operations, etc.), and corrective measures which involve levee system adaptation in terms of functions and components.

The second part of the paper deals with integration of risk reduction measures into the specific failure mode and effects process developed by Irstea these past few years to

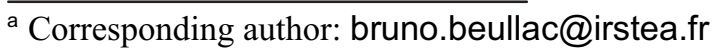


analyse levee systems failures [5]. This method, which is based on functional analysis and failure modes and effects processes analysis, leads to the identification of the different inundation scenarios and breach scenarios of flood protection systems. The paper presents a process to identify risk reduction measures and integrate and characterize them in these two types of failure scenarios, and so improve the quality of the levee systems performance modelling and assessment activity.

\section{The risk reduction measure concept and its adaptation to levee system}

\subsection{Definition for risk reduction measures}

In its industrial application, a risk reduction measure is defined as a technical and/or organizational element, necessary and sufficient to ensure a safety function [2]. Safety functions are functions whose objectives are to reduce the probability and/or the consequences of undesirable events.

In a risk analysis process, undesirable events lead to system failures. A failure being the inability for a system to achieve a defined performance threshold for a given function [1], security functions objectives of risk reduction measures are then to reduce the probability and/or the consequences of failures of studied system components functions. To reduce the probability and/or the consequences of failures means to prevent and/or relay these failures. To prevent failures means to identify and correct the possible problems before they lead to failures or to avoid the occurrence of situations which can lead to failures. To relay failures means to identify failures after their occurrence and act to substitute failed elements to maintain system function.

The main function of a levee system is flood protection; levee system failure analysis is a process of treatment and combination of data whose objective is to estimate how, where and with which probability a levee system might fail and thus no longer protect against flood [1].

Therefore, and according to the definitions cited above, in a levee systems application we chose to define risk reduction measures as technical and/or organizational security elements which ensure safety functions, whose objectives are to prevent and/or relay the development of levee systems failure scenarios and thus to prevent and/or limit the occurrence or intensity of unwanted inundations in leveed areas.

\subsection{Risk reduction measures classification}

Different types of risk reduction measures are classically identified in industrial risk analyses (Figure 2).

That classification which first distinguishes human measures and technical measures finally identifies five types of risk reduction measures. Since we found them adapted, we propose to directly apply these different types of risk reduction measures (RRM) to levee systems.

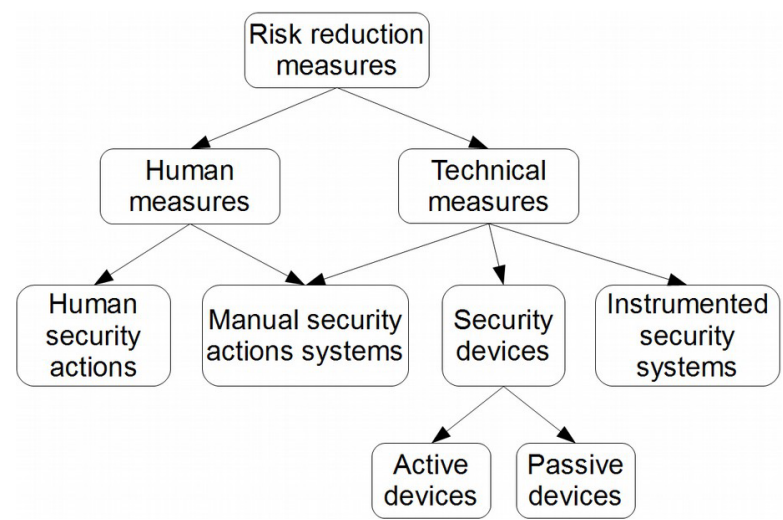

Figure 2. The different types of risk reduction measures in industrial context [6]

We propose to distinguish:

- Human security actions: security functions performed by human beings with no help from technical security element. For levee systems, an example of such a RRM could be a planned levee inspection which can lead to an alert because of identification of deteriorations and finally to a levee reparation after assessment and decision making. The security function of this example of RRM is to maintain levee structural performance;

- Manual security actions systems: systems combining human actions and technical security elements to perform security functions. For levee systems, an example of such a RRM could be an embankment deformation measurement system which allows an operator to identify significant deformations and finally to alert leading to assessment and decision making and levee reparation. The security function of this example of RRM is to maintain levee structural performance;

- Passive security devices: technical autonomous static devices automatically and physically performing security functions beyond given loading thresholds. For levee systems, an example of such a RRM could be a spillway which floods above a given water level, in order to relieve water level in other parts of the system to avoid breaching. The security function of this example of RRM is to control hydraulic load on levee system and prevent breaches occurrences on other levee segments;

- Active security devices: technical autonomous mechanical devices automatically and physically performing security functions beyond given loading thresholds. For levee systems, an example of such a RRM could be a flap gate which opens and floods after water level in leveed area reaches a given threshold. The security function of this example of RRM is to control hydraulic load on levees and prevent breaches on levee system when the water level decreases in the river and the leveed area is inundated;

- Instrumented security systems: technical systems comporting measuring tools and autonomously performing security functions if predefined values are measured. For levee systems, an example of such a RRM could be a water level measuring tool which autonomously opens (or closes) a gate when water level exceeds a critical threshold. The security function of this example of RRM is again to control hydraulic load on levees and prevent breaches on levee system. 


\subsection{Sub-functions of risk reduction measures}

Except for passive and active security devices, which automatically and physically perform their security functions in direct response to loading conditions, a risk reduction measure performs its security function through three different steps (Figure 3).

These three steps are:

- Step 1: detection: identification of a failure, a degradation of a function of a system's component or of a situation known as a potential cause of failure (loading for instance). This step can be done by human operators (levee inspections or watch during high water event), by human operators using measuring tools (for example: reading of measured water levels, temperatures, deformations...), or by autonomous measuring tools linked to computers or electric automatic systems (for example: measure of water levels, temperatures, deformations...);

- Step 2: information treatment: analysis of the information obtained through the detection step, and decision making to identify corrective solutions to prevent and/or relay failure scenarios. This step can be done by human analysis and decision making (for example: diagnosis of levee structural performance and definition of repair solutions), or by computers or other type of automat programmed to analyse data and take predetermined decisions (for example: autonomously order a gate opening beyond a predetermined water level);

- Step 3: action: execution of the corrective solutions, chosen through the information treatment step, to prevent and/or relay failure scenarios. This final step can be done by humans (for example: make repairs), by human operators using technical security elements (for example: an operator which manually opens a gate) or by autonomous technical security elements (for example: autonomous opening of a gate).

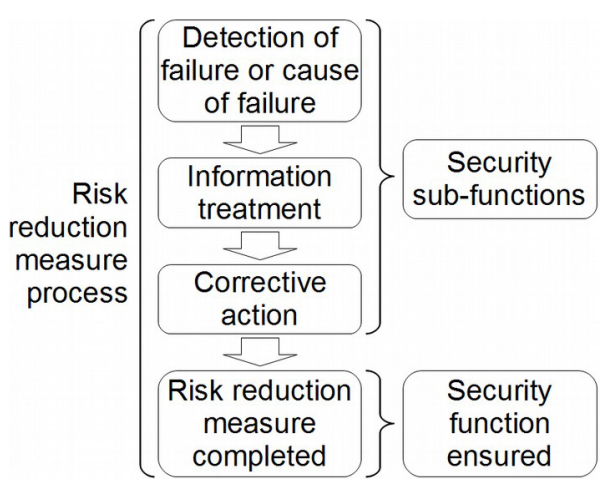

Figure 3. The risk reduction measure process and the security subfunctions sequence to ensure security functions

As illustrated in figure 3, these three steps form a sequence of security sub-functions which is needed to perform a security function. A risk reduction measure (except for passive and active security devices) results from the sequenced combination of this three security subfunctions.

\subsection{Risk reduction measures characterization}

\subsubsection{Independence requirement}

In a process of risk analysis of a system, to identify a system's element as a security element and thus as a risk reduction measure, results from a methodological choice. However, to be considered as a risk reduction measure, a system's element has to respect a requirement of independence [6-7].

Firstly, to be identified as a RRM, a system's element must be independent from the failure scenarios or the causes of the failure scenarios which it prevents or limits development. For example, if an inundation in a leveed area results from an operator who failed in closing a floodgate, a corrective action of the same operator to fix the failure and finally close the gate cannot be a RRM. In fact, the operator being the same, such corrective action is dependent from the cause of the failure.

Furthermore, a system's element cannot be identified as a RRM if its performance can be deteriorated because of a failure which it is supposed to prevent or limit development. For example, a spillway whose security function is to prevent breaches on a levee system over a given loading condition cannot be identified as a RRM if it does not resist to such a loading condition.

Finally, to be integrated in the estimation of a failure scenario probability as independent events, the risk reduction measures involved in that scenario must be independent from each other. For example, in a failure scenario, if two different human security actions or manual security actions systems prevent or relay the failure of two different functions, these two RRM are dependent from each other if the operator is the same.

\subsubsection{Characterization criterions}

To be taking a RRM in account in the estimation of a system failure probability, this one has to be characterized according to three different criterions [6]: response time, efficiency and reliability.

The response time criterion of a RRM corresponds to the space between the detection of a function failure or degradation and the moment when the security function of this RRM is totally completed. For example, the response time for a RRM whose security function is to maintain levee structural performance, corresponds to the space between the levee inspection and the levee reparation, after assessment and decision making, if levee deteriorations are identified.

The response time criterion is not applicable for active and passive security devices RRM since they directly respond to loading conditions.

This criterion is used as a first evaluation step, to evaluate if the response time of a security measure is adapted to the kinetics of the undesirable event it aims to prevent or whose it aims to limit the consequences. Thus, this criterion permits to evaluate if a security measure can be accepted as an adapted risk reduction measure, to perform a security function for a given technical function.

To be accepted as a RRM, the response time of a security measure must be:

- significantly inferior to the kinetics of the function failure 
the RRM aims to prevent: for example, for levee maintenance RRM, response time criterions must be short enough to minimize the possibility of extreme event before levee deteriorations repairs;

- or, for a RRM which relays a function failure, significantly inferior to the kinetics of the consequences of the function failure: for example, for a RRM which relays levee breaches with temporary levees, the response time criterion must permit to significantly limit water entrance in leveed area. For this second case, response time criterion can also be used to estimate the function failures consequences for spaces between failures and RRM actions completed.

The efficiency criterion traduces the capacity of a RRM to ensure the security function it has been chosen for (to prevent and/or relay a function failure). The efficiency criterion of a RRM, can be evaluated in terms of percentage of accomplishment of its security function.

This evaluation is mainly conducted through the verification of:

- the adapted conception of the RRM considering the function failure to prevent and/or relay;

- the resistance of the RRM considering the involved phenomena (hydraulic phenomena...) and in terms of security for operators involved in RRM;

- the possible deterioration of the RRM because of ageing (for technical RRM).

For example, levee maintenance RMM with weekly inspections are far more efficient than ones with monthly inspections; or, an active security device RRM comporting a $100 \mathrm{~m}^{3} / \mathrm{s}$ flap gate is twice efficient than one with a rate of flow of $50 \mathrm{~m}^{3} / \mathrm{s}$.

This evaluation, which relies on rather classical engineering analysis and calculation (design), can also be used in risk analysis to estimate effects of functions failures which take place despite the action of risk reduction measures (for RMM with an efficiency criterion lower than $100 \%)$.

The reliability criterion $(R C)$ of a $\mathrm{RRM}$ traduces the reduction of function failure probability $(F R)$ due to the RRM acting on this function. It corresponds to the probability of failure of a given RRM.

We propose to evaluate $R C$ and $F R$ as following:

$$
\begin{gathered}
10^{-R C}<F R \leq 10^{-(R C-1)} ; \text { for } R C>0 \\
F R=1 \text { for } R C=0
\end{gathered}
$$

With: $R C=0$ for an unreliable $\mathrm{RRM} ; R C=1$ for a low reliability; $R C=2$ for a medium reliability and $R C=3$ for a high reliability

The reliability criterion is mainly evaluated through the verification of:

- human and material resources;

- actions planning;

- crisis exercises;

- maintenance;

- accessibility;

- reliability feedback;
- formation of operators...

For example, if the reliability of a RRM is evaluated as medium, its $R C$ value is 2 and the application of (1) gives $10^{-2}<F R \leq 10^{-1}$.

On the other hand, if a RRM is evaluated as unreliable, its $R C$ value is 0 and the application of (2) gives $F R=1$.

\subsubsection{Performance evaluation}

The objective of the evaluation of the performance of risk reduction measures is to calculate the effective function failure probability reduction $\left(F R_{\text {eff }}\right)$ which is involved by risk reduction measures.

We propose to combine the efficiency criterion $(E)$ and the reliability criterion $(R C)$, defined above, to calculate $F R_{\text {eff }}$ and get a better estimation of failure probability reduction resulting from risk reduction measures actions.

The response time criterion is not used to calculate the effective function failure probability reduction. In fact, as explained in part 2.4.2, the response time criterion is only used as a first evaluation step, to evaluate if a security measure can or cannot be accepted as an adapted risk reduction measure, considering its response time criterion and the kinetics of the undesirable event it aims to deal with.

To calculate $F R_{\text {eff }}$ and combine the efficiency criterion $(E)$ and the reliability criterion $(R C)$, we propose the following method:

$$
\begin{gathered}
10^{-E . R C}<F R_{\text {eff }} \leq 10^{-E .(R C-1)} ; \text { for } R C>0 \\
F R_{e f f}=1 ; \text { for } R C=0
\end{gathered}
$$

With: $R C=0$ for an unreliable RRM; $R C=1$ for a low reliability; $R C=2$ for a medium reliability; $R C=3$ for a high reliability and $E$ in percentage

Then, we propose to calculate the probability $\left(P_{f F R}\right)$ of a function failure $\left(P_{f}\right)$ combined with the action of a linked $\operatorname{RRM}\left(F R_{e f f}\right)$, as following:

$$
P_{f F R}=P_{f .} F R_{e f f}
$$

For Example, if a technical function has a probability of failure $3.10^{-5}<P_{f} \leq 3.10^{-4}$ and an associated RRM with a medium reliability $R C=2$ and an evaluated efficiency value $\mathrm{E}=70 \%$, then, the application of (3) gives $0,04<F R_{\text {eff }} \leq 0,2$ and the application of (5) gives $1,2.10^{-6}<P_{f F R} \leq 6.10^{-5}$.

On the other hand, if the associated RRM is evaluated as unreliable, its $R C$ value is 0 and the application of (4) gives $F R_{\text {eff }}=1$ regardless of the $\mathrm{E}$ value. Then, the application of (5) gives $P_{f F R}=P_{f}$.

\section{Integration of risk reduction measures in levee system failure analysis process}

The failure analysis process in which we propose to integrate RRM is based the methods developed by the French research institute Irstea for functional analysis and failure modes analysis of levee systems [5-8]. These methods, which are both based on the structural/hydraulic failure model (figure 4) describe in $[1 ; 5 ; 9]$, can together be 
used to analyze, identify and represent levee systems failure scenarios in levee systems flood risk analyses.

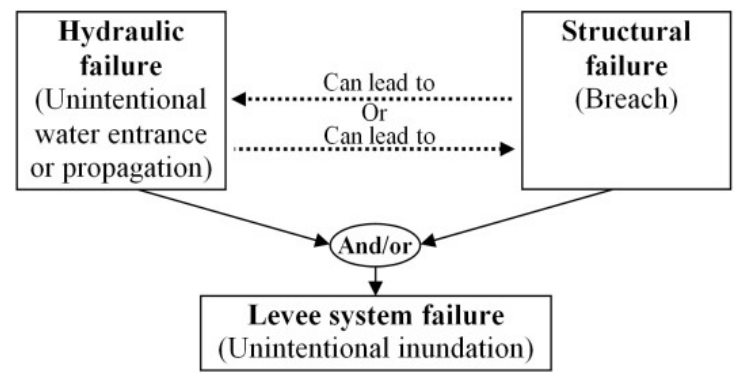

Figure 4. Levee systems failure model [1-5]

\subsection{Integration in the functional analysis process}

In this method, functional analysis of levee systems is undertaken at three different scales of analysis [5].

- Scale 1: analysis of the levee system as a whole, to determine and characterize its main functions (to protect against floods...) and its functions constrained by its environment (to resist to hydraulic loading, to be maintained, to respect State regulation obligations...). Main functions define the main objectives of the levee system and constrained functions define the constraints the system has to deal with in order to realize its main functions. Main functions and constrained functions of the levee system define the frame in which scales 2 and 3 analyses must be undertaken to determine technical functions.

- Scale 2: analysis of the subsystems that form the levee system (levees, spillways, water storage area...), to determine and characterize their hydraulic technical functions (to prevent water entrance in leveed area, to control water entrance in leveed area, to store water...).

- Scale 3: analysis of the structural components of subsystems cross sections (protections against erosion, levee bodies, filters, drains...) that form structurally homogeneous sections of levees, to determine and characterize their structural technical functions (to protect against erosion, to stabilize, to filter, to drain...).

Levee systems failure scenarios being studied on scales 2 and 3 [5], RRM integration in functional analysis must be done both on these analysis scales.

To do so, we propose to complete the functional analysis process [5] with the identification and characterization of the existing security elements which are associated with levee subsystems or structural components, to prevent or relay the failure of their technical functions. This new part of functional analysis can especially be conducted through the analysis of the security interactions which can exist between some elements of a levee system. For example, a security interaction can be identified between a spillway and the other segments of a levee system whose loading is controlled by the spillway.

Beyond technical elements (levee sub-systems or structural components) we propose that this analysis also considers organizational security measures. These measures, which can be for example inspection patrols, levee maintenance, and so forth, have to be identified on the scale
1 analysis, as constrained functions which are needed to ensure the levee system main function (protection against floods). We propose that these organizational security measures be identified as levee systems elements in the functional analysis of scales 2 and 3 (as for the levee patrol example in table 1).

This analysis finally aims to define the security functions or security sub-functions of the security elements which are identified.

Table 1 presents examples of some functional analysis results including the identification of some security functions and security sub-functions. That principle, which is both applicable to analysis of scales 2 and 3 , must be applied separately for each scale of analysis of the levee system. As we can see with the spillway example in table 1, system elements can support several functions including both security functions and technical functions. Furthermore, the identification of security sub-functions leads to the identification of the security functions and thus the RRM which include them.

\begin{tabular}{|c|c|c|}
\hline $\begin{array}{l}\text { System } \\
\text { elements }\end{array}$ & $\begin{array}{l}\text { Types of } \\
\text { functions }\end{array}$ & Descriptions of functions \\
\hline Levee body & $\begin{array}{l}\text { Technical } \\
\text { function }\end{array}$ & To stabilize the levee segment \\
\hline $\begin{array}{c}\text { Deformation } \\
\text { measurement } \\
\text { system }\end{array}$ & $\begin{array}{l}\text { Security } \\
\text { sub- } \\
\text { function }\end{array}$ & $\begin{array}{l}\text { To identify deformations in the } \\
\text { levee body }\end{array}$ \\
\hline \multirow{2}{*}{ Levee patrol } & $\begin{array}{l}\text { Security } \\
\text { sub- } \\
\text { function }\end{array}$ & To look for levee deteriorations \\
\hline & $\begin{array}{l}\text { Security } \\
\text { sub- } \\
\text { function }\end{array}$ & $\begin{array}{c}\text { To look for hydraulic events } \\
\text { evolutions }\end{array}$ \\
\hline \multirow{3}{*}{ Spillway } & $\begin{array}{l}\text { Technical } \\
\text { function }\end{array}$ & $\begin{array}{l}\text { To prevent water entrance in leveed } \\
\text { area before a given water level }\end{array}$ \\
\hline & $\begin{array}{l}\text { Technical } \\
\text { function }\end{array}$ & $\begin{array}{c}\text { To control water entrance in leveed area } \\
\text { above a given water level }\end{array}$ \\
\hline & $\begin{array}{l}\text { Security } \\
\text { function }\end{array}$ & $\begin{array}{l}\text { To control hydraulic load on levee } \\
\text { system and prevent breaches } \\
\text { occurrences on other levee segments }\end{array}$ \\
\hline
\end{tabular}

Table 1. Principle of the identification of security functions and security sub-functions in functional analysis (for examples of analysis of scales 2 and 3 )

\subsection{Integration in the failure analysis process}

This process of failure analysis of levee systems is based on the principle of failure modes and effects analysis (FMEA) which is well adapted to hydraulic works [10-11]. It identifies failure modes of studied functions, their causes and their effects. Effects of functions failures being causes of other functions failures, this method allows identification of failures scenarios.

As described in [5], this method is based on the results of the functional analysis method presented above. The analysis is conducted both at scale 2 (hydraulic functions failures) and scale 3 (structural functions failures). It leads to the identification of:

- hydraulic failure scenarios: successions of events and 
hydraulic functions failures that lead to unwanted or unplanned inundations of the leveed area. These scenarios end when no more hydraulic failure occurs and the levee system returns to a new stabilized state;

- structural failure scenarios: processes which involve both physical and functional phenomena and lead to breaches scenarios. Such scenarios can stop when external loadings or actions cease. The state of the levee is then deteriorated (which means that the functions of some of its components are degraded or failed) or ruined (meaning that there is a breach) but not necessarily. The scenario can then start over from a deteriorated state when a new loading/action occurs.

To integrate risk reduction measures in the failure modes analysis process, we propose to distinguish two types of RRM:

- preventing RRM: preventing function failures, they act before technical function failures and have an effect on causes of failures or on degradations of functions. Security functions of such RRM are for example: to maintain the performance of the structural components of the levee system; to control hydraulic load on levee system and prevent breaches occurrences for other levee subsystems...;

- relaying RRM: relaying function failures, they act after technical function failures and have a direct effect on failed functions to substitute failed elements. Security functions of such RRM are for example: to relay the failure of the external protection component of the levee segment, to ensure its "protection against external erosion" technical function; to relay the failure of a breached levee segment, to ensure the flood protection technical function of this subsystem...

Figure 5 shows how these two different types of RRM can be integrated in hydraulic failures scenarios.

In hydraulic failure scenarios, preventing risk reduction measures aim to identify and correct the causes of subsystems failures. These causes can be of four different types:

- errors in the design or construction of subsystems: for example an error in the crest elevation of a subsystem which is lower than the planned level and leads to a lower level of protection for the levee subsystem;

- modifications in the morphology of the environment of the levee system: for example a modification in the riverbed elevation (due to a flood event) close to the subsystem which is higher than the normal level and then results in a lower level of protection for the levee subsystem;

- operational failures: for example a failure in the closure of a flood gate which leads to an unplanned situation for the levee subsystem and an unwanted inundation;

- breaches in levee subsystems: such events result from structural failures of levee segments and can lead to unwanted inundations.

Relaying risk reduction measures in hydraulic failure scenarios aim to substitute the functions of failed subsystems. For example, the identification of a breached levee and the emergency construction of a temporary levee is a relaying RRM for levee failures.

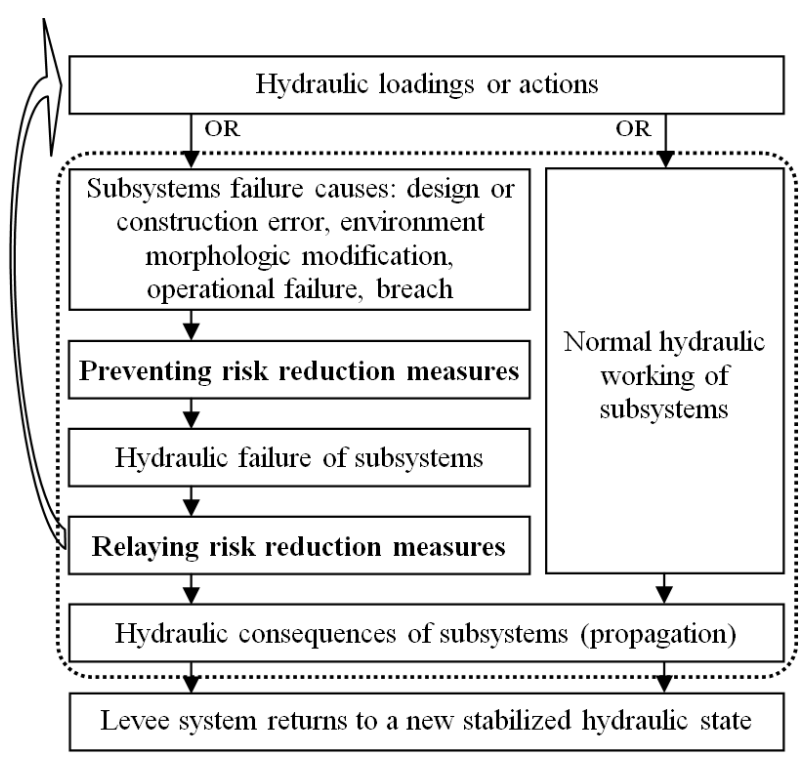

Figure 5. Integration of preventing and relaying risk reduction measures in hydraulic failure scenarios

Figure 6 shows how these two different types of RRM can be integrated in scenarios of structural failures.

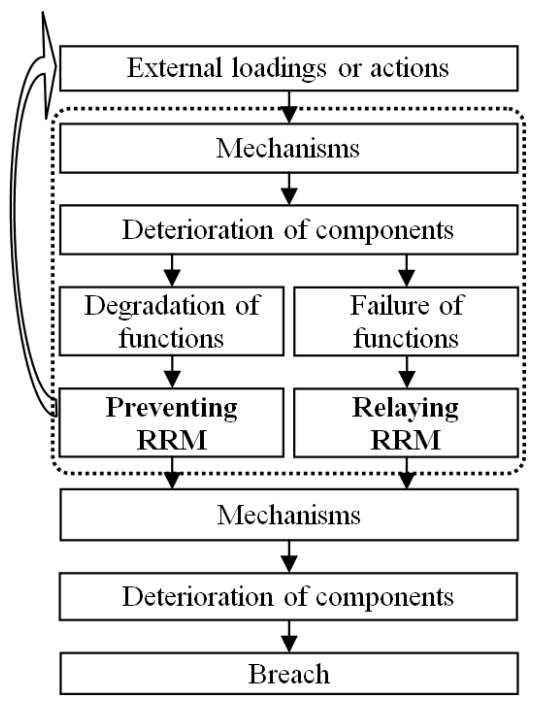

Figure 6. Integration of preventing and relaying risk reduction measures in structural failure scenarios

In structural failure scenarios, preventing risk reduction measures act on deteriorated components whose technical functions are degraded. These RRM are mainly maintenance RRM such as for example: planned levee inspections which lead to alert in case of levee deteriorations and finally to repairs after assessment and decision making.

Relaying risk reduction measures in structural failure scenarios are planned to substitute components whose technical functions are totally lost or are in the process of being lost. These RRM are mainly emergency RRM such as for example: levee patrols during floods which lead to alert in case of deterioration of the levee segment external protection and finally to the emergency reinforcement of the 
levee surface with sand bags to limit deterioration due to external erosion.

\subsection{Decision-making and risk reduction measures}

At the end of its process, a risk analysis of levee system leads to decision-making which first consists in risk evaluation and then in the definition of new risk reduction measures (figure 7). The objective of risk evaluation is to determine the significance to society of flood risk associated with the levee system. That step, which is not a step of risk analysis but the first step of decision-making, aims to enable decision-makers to determine whether or not to proceed further with the definition of measures to reduce flood risk.

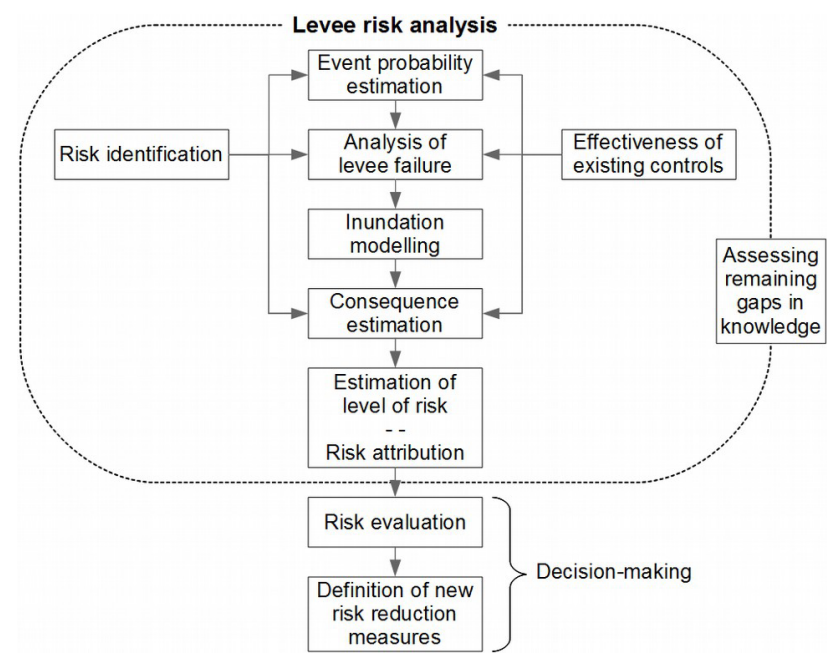

Figure 7. Decision-making: risk evaluation and definition of new risk reduction measures (Based on [1])

The measures which are defined to answer to the results of risk evaluation can be of two different types. They can be new risk reduction measures introducing new security functions for some levee system components (as defined in this paper), or corrective measures such as repairs or the planning of structural modifications of the levee system to correct design issues.

Corrective measures can be considered as risk reduction measures in the special context of the decision-making process which follows a risk analysis (figure 7). To validate the chosen risk reduction program the probabilities of failure scenarios must be recalculated taking in account these new risk reduction measures.

However, once executed, corrective measures resulting in structural modifications of the levee system become new components of this levee system, with their own hydraulic or structural technical functions instead of existing RRM. As such, they should be considered as regular components of the system and not as RRM in ulterior risk analyses.

For example, if it is decided to reinforce a levee segment, whose internal erosion performance is judged critical at the end of risk analysis, by adding a filter/drain device in its levee body, the decision-making process must recalculate the failure probability of the levee segment considering this reinforcement as a new RRM involving a failure probability reduction (see 2.4) for the levee segment. However, in an ulterior risk analysis, when the reinforcement will be realised, the new filter/drain device will have to be identified as a structural component of the levee segment in the functional analysis, with its own evaluated failure probability, and no more as a RRM.

\section{Conclusions}

The paper shows that the industrial concept of risk reduction measures can be adapted to the process of risk analysis of levee systems.

The identification of risk reduction measures can be made through the functional analysis and failure mode analysis process by the identification of security functions and security sub-functions of levee systems elements and their associated technical functions. Once their independence has been verified, the identified risk reduction measures can be characterized in terms of efficiency and reliability to evaluate their performance.

Risk reduction measures are integrated in the levee system failure analysis process as preventing or relaying security measures which take places in hydraulic failure scenarios or structural failure scenarios. The evaluation of their performance permits to enhance the calculation of levee systems failure probabilities for a better estimation of flood risk associated to levee systems. For newly proposed RRM it allows to estimate the relative efficiency of every RRM and so to better choose among them.

The principles exposed in the paper are propositions for a better analysis and evaluation of risk reduction measures of levee systems. The definition of these principles has been initiated during a student traineeship whose objective was to identify and analyse risk reduction measures references for industrial and dam applications considering the specificities of risk analysis of levee systems. These principles aim to improve methods of risk analysis of levee systems for a better levee management and decision-making. They still have to be tested for different types of levee systems configurations, to optimize the integration of risk reduction measures in the levee systems failure analysis process.

\section{References}

1. Ciria, MEDDE (Ministère de l'Ecologie du Développement durable et de l'Energie), USACE (US Army Corps of Engineers). (2013) The International Levee Handbook. CIRIA, London.

2. MEEDDAT (Ministère de l'Ecologie, de l'Energie, du Développement Durable et de l'Aménagement du Territoire) (2010) - Circulaire du 10 mai 2010 récapitulant les règles méthodologiques applicables aux études de dangers, à l'appréciation de la démarche de réduction du risque à la source et aux plans de prévention des risques technologiques (PPRT) dans les installations classées. NOR : DEVP1013761C. 
3. CIGB ICOLD (2005) Risk Assessment in Dam Safety Management: A Reconnaissance of Benefits, Methods and Current Applications. ICOLD Bulletin 130. International Commission on Large Dams.

4. MEEDDAT (Ministère de l'Ecologie, de l'Energie, du Développement Durable et de l'Aménagement du Territoire) (2012) - Guide de lecture des études de dangers de barrages, $55 \mathrm{p}$.

5. Tourment R., Beullac B., Degoutte G. (2015) - Etudes de dangers des systèmes de protection contre les inondations : une méthode d'analyse de la défaillance La Houille Blanche, $\mathrm{n}^{\circ} 1,41-55,15 \mathrm{p}$. DOI: 10.1051/lhb/2015006.

6. INERIS (Institut National de l'Environnement Industriel et des Risques) (2008) Rapport d'étude $\mathrm{n}^{\circ}$ DRA-08-95403-01561B Evaluation des performances des Barrières Techniques de Sécurité (DCE DRA-73) Evaluation des Barrières Techniques de Sécurité - $\Omega$ 10, 59p. http://www.ineris.fr/centredoc/Omega_10_Evaluation_ BTS_v2_0908_web.pdf

7. INERIS (Institut National de l'Environnement Industriel et des Risques) (2009) Rapport d'étude $n^{\circ}$ DRA-09103041-06026B Maîtrise des risques accidentels par les dispositions technologiques et organisationnelles - DRA 77 - démarche d'évaluation des Barrières Humaines de $\begin{array}{lllll}\text { Sécurité } & - & \Omega & 20, & 66 \mathrm{p} \text {. }\end{array}$ http://www.ineris.fr/centredoc/omega-20-barriereshumaines-v2-1386233972.pdf

8. Tourment R., Beullac B., Deniaud Y., Simm J., Wallis M., Sharp M., Pohl R., van Hemert H., (2013).'De l'EDD des digues en France aux travaux de l'ILH sur les mécanismes élémentaires et les scénarios de défaillance'. 2nd colloque national - Digues2013, MEDDTL / CFBR / Irstea, Digues Maritimes et Fluviales de Protection contre les Submersions, Aix-enProvence, 288-297.

9. Simm J., Wallis M., Smith P., Tourment R., Veylon G., Deniaud Y., Durand E., McVicker J., Hersh-Burdick R. (2012). 'The significance of failure modes in the design and management of levees-a perspective from the International Levee Handbook team'. 2nd European conference on Flood Risk Management, FLOODrisk2012, Rotterdam, 9 p.

10. Modarres, M. (1993). What every engineer should know about reliability and risk analysis. Marcel Dekker Publisher, Inc., New York.

11. Peyras, L., Royet, P., Boissier, D. (2006) Dam Ageing Diagnosis and Risk Analysis: Development of Methods to Support Expert Judgment. Canadian Geotechnical Journal, Vol. 43, 2006, 169-186. 